\title{
DO PORTO AO PALCO, UM ESTUDO DOS CONCEITOS DE CORPOREIDADE E CORPORALIDADE
}

\author{
M. G. SOARES, G. L. KANEKO e J. GLEYSE \\ Doutora em Educação. Professora da Universidade do Estado do Pará \\ Especialista em Fisiologia do Corpo e Mestranda em Educação pela Universidade do Estado do Pará. \\ Doutor em Ciência da Educação e Professor da Université de Montpellier/França \\ martagenu@gmail.com
}

Artigo submetido em novembro/2015 e aceito em dezembro/2015

DOI: 10.15628/dialektike.2015.3725

\section{RESUMO}

Trata-se de um estudo sobre a acepção de corpo, fenômeno estudo na perspectiva materialista e fenomenológica. Objetiva identificar a relação epistêmica entre os conceitos de corporeidade e corporalidade ao estabelecer parâmetros que relacionam esses conceitos pela ótica das teorias do conhecimento do materialismo histórico dialético e da fenomenologia. De abordagem etnográfica, na metodologia utiliza instrumentos de coleta de dados aplicados com a observação do cotidiano, protocolo sociobiológico e trata os dados por categorias de análise que emergem do aporte teórico utilizado e da observação do trabalho de estivadores e do culto ao corpo de fisiculturistas. Conclui que as terminologias corporeidade e corporalidade não são obstáculos epistêmicos para a compreensão do fenômeno corpo na relação com o trabalho.

PALAVRAS-CHAVE: Epistemologia; Corpo; Trabalho.

\section{FROM THE SEAPORT TO THE STAGE, A STUDY OF THE CORPOREALITY AND CORPORALITY CONCEPTS}

\section{RESUMO}

This study is about the meaning of body, phenomenon studied in the materialist and phenomenological perspective. It aims to identify the epistemic relation between the concepts of corporeity and corporeality establishing parameters that relate these concepts based on the theories of knowledge of dialectical historical materialism and phenomenology. With ethnographic approach, in the methodology it utilizes tools of data collection applied to the observation of everyday life, sociobiological protocol and it treats the data by categories of analysis emerging from the theoretical approach and observing the work of stevedores and the cult of bodybuilding body. It is possible to conclude that the terminologies corporeity and corporeality are not epistemic obstacles to the understanding the body phenomenon in relation to work.

KEYWORDS: Epistemology; Body; Work. 


\section{CORPO E CONHECIMENTO: APRECIAÇÕES INTRODUTÓRIAS PARA O ESTUDO}

Ao longo da carreira docente no ensino superior e das investidas na pesquisa na área das práticas corporais, tenho investigado o fenômeno corpo e sua representação social, a partir do simbólico e da materialização de práticas de ensino que estão no campo da cultura, mas sempre com o objetivo de sistematizar conhecimento para a aplicação didáticopedagógica no campo acadêmico, quando se estabelece a relação entre pesquisa e ensino.

Compreender os conceitos, que advém de diferentes interpretações da realidade, de teorias pedagógicas, de abordagens educativas, que permeiam o corpo e as práticas corporais favorece a organização do trabalho pedagógico, de pesquisadores-docentes, pautado em referencial das teorias do conhecimento que tem procedimento educativo a partir do estudo da realidade, da organização do conteúdo para a aplicação do conhecimento articulado com a cultura e a territorialidade (no sentido da especificidade do lugar).

Ao construir, neste estudo, aporte teórico sobre a relação corpo e trabalho (sustentado pelos autores que referenciam essa análise aqui apresentada), e este em processo de sujeição, na ação cotidiana de sujeitos inseridos em diferentes espaços sociais, é possível compreender o comportamento social e o trato com o corpo nas atividades singulares do dia a dia e dessa forma estabelecer referências científicas para condutas sociais em diversos setores da sociedade.

Considerando o estilo de vida na sociedade contemporânea e os hábitos relacionados com o cuidado do corpo, este estudo é aporte teórico que trata de conceitos fundantes e correlacionados: corporeidade e corporalidade. Ao analisar o fenômeno corporeidade a partir de Merleau-Ponty, Gleyse e estudiosos da fenomenologia se faz um paralelo teórico com a terminologia adotada nos estudos sócio antropológicos, a corporalidade, com a finalidade de estabelecer a essência que subjaz esse fenômeno por meio das ideias e princípios expressos nos dos campos de estudo.

$\mathrm{Na}$ etapa subsequente a este mapeamento conceitual feito, é investigado o cotidiano do trabalhador estivador do Cais e do fisiculturista que destina um tempo do dia para o condicionamento físico em espaços específicos para tal. A análise se pauta em dois conceitos: a corporeidade e a corporalidade com acepções para o fenômeno corpo em sua condição de existência, a partir as áreas do conhecimento sociológico e filosófico.

Em verdade, é questão para o estudo o fenômeno corpo na percepção dos sujeitos envolvidos. Para tanto, na investigação sobre corporeidade e corporalidade, são consideradas as enunciações sobre a acepção corpo e seu uso nas atividades físicas do cotidiano dos sujeitos.

O estudo recupera a abordagem do conceito corpo e a instrumentalização deste, tanto na busca do desenvolvimento das atividades do trabalho com as técnicas corporais como nas práticas sociais, em constructo teórico de Jacques Gleyse e fenomenólogos, e leituras de perspectiva materialista, quando reúne seguidores desses autores que ampliam o marco teórico definido nas teorias do conhecimento do materialismo e da fenomenologia. A apreciação sobre o processo de sujeição (posto que tanto os estivadores quanto os 
fisiculturistas se colocam em conformidade com as atividades que desenvolvem, tornandose dependentes das condições e uso do corpo em acordo com o trabalho que desenvolvem) está imanente nas práticas sociais dos sujeitos participantes e na condição de ser e estar no lugar ocupado por eles.

A questão científica aportada na acepção de corpo se constitui em responder a relação epistêmica entre os conceitos de corporeidade e corporalidade. Para estabelecer essa aproximação conceitual, são elaboradas outras questões que colaboram com a delimitação teórica e perpassam pelo: comportamento laboral, pois investiga as práticas corporais do trabalhador braçal no exercício da profissão e aquelas exercidas no tempo/espaço livre; modo como os profissionais do fisiculturismo desenvolvem as atividades cotidianas e praticam atividades físicas em espaços específicos; saber sobre a relação com a saúde e como os conceitos de corporeidade e corporalidade designam o corpo saudável.

A questão científica elaborada ou problema de estudo, ao ser respondida encerra o ciclo inicial do estudo e possibilita o início da pesquisa empírica para caracterizar as representações sociais sobre o trato com o corpo e colaborar com aporte para os sistemas de pensamento científico em pesquisas, estudos, ensaios que versam sobre práticas sociais no âmbito das práticas corporais nos diversos setores da sociedade.

Os objetivos aqui traçados, correspondentes às questões de estudo compreendem a delimitação do conceito de corporeidade e corporalidade utilizado na Fenomenologia e estudos sociológicos com abordagem do Materialismo, respectivamente, a partir de autores que tratam sobre esses conceitos quando analisam o comportamento social e as práticas corporais.

Caracterizam ainda a concepção de corpo e técnica corporal que instrumentaliza o corpo em práticas laborais; identificam que conceito de corpo subjaz práticas que objetivam corpos eficientes e apresentam indicativos epistêmicos para o trato com o corpo saudável no sentido lato.

De abordagem dialética, o procedimento metodológico adota o estudo de revisão para mapear os conceitos de corporeidade e corporalidade a serem investigados na fase bibliográfica, o que permitirá a continuidade da pesquisa quando de campo na próxima etapa.

O processo metodológico de organização de pesquisa pauta-se no mapeamento e usa o acompanhamento de percurso, que implica em processos de produção e categorização. As categorias de análise, expressas nas ideias e princípios dos conceitos estudados, serão adotadas na medida em que as obras forem mapeadas identificando-se os conceitos chave desse estudo, e analisadas em suas essências quando de suas articulações com a concepção de corpo e conexões com as teorias do conhecimento forem aplicadas.

Como revisão bibliográfica (ALVES-MAZZOTTI, 2002) tem dois propósitos: a construção de uma contextualização para o problema e a análise das possibilidades presentes na literatura consultada para a concepção do referencial teórico da pesquisa. Como técnica, a análise de conteúdo, que permite a descrição sistemática, objetiva e quantitativa dos conceitos investigados e a frequência com que são analisados. 
O desenvolvimento e organização do trabalho estão aportados no levantamento da produção sobre a relação corpo e sociedade e dos estudos relacionados às práticas corporais que analisam o comportamento social frente ao trabalho na perspectiva da saúde.

O estudo sobre os conceitos de corporeidade e corporalidade, no formato artigo, compreende nos procedimentos metodológicos a coleta de dados que com entrevista com o Dr. Jacques Gleyse sobre o tema Corporeidade, princípios e ideias do corpo vivido e corpo sujeito, desenvolvidos em pesquisas desse autor; a apreciação da obra de Jacques Gleyse e seus colaboradores com o tema corporeidade; a apreciação da tese "A instrumentalização do corpo" de Jacques Gleyse; o mapeamento do conceito de corporalidade na produção sobre esse conceito nos estudos, de perspectiva sócia histórica, encontrada nos periódicos e livros publicados pelos autores estudados.

Após o primeiro momento investigativo de estudo bibliográfico se aplica a pesquisa de campo para identificar o cotidiano de dois grupos de sujeitos com estilos de vida bem caracterizados: o grupo de trabalhadores estivadores do Cais na cidade de Belém do Pará, que no labor necessita de corpos eficientes e o grupo de fisiculturistas que, objetiva, corpos eficientes.

A investigação empírica contém três instrumentos de coleta de dados: o diagnóstico para a caracterização dos sujeitos, em que se aplica instrumento de teor sociobiológico, a anamnese e a filmagem do cotidiano preservados os cuidados éticos e devidamente autorizada por termo de consentimento livre e esclarecido.

A técnica de multimétodos tem suporte em Chizzotti (2003) que anuncia que pela multiplicidade de instrumentos técnicos se alcança o sentido do fenômeno e a possibilidade de interpretá-lo de forma mais próxima a essência. É na observação do cotidiano que os dados são coletados e desenvolvidos, quando da apreciação conjunta com os sujeitos. Momento em que é feita a análise comentada e categorização das percepções dos sujeitos sobre os conceitos corpo, corporeidade e corporalidade com articulação às ideias de saúde e qualidade de vida.

A fim de compreender o estudo realizado, o texto se organiza em momentos que explicitam os conceitos corporeidade e corporalidade no sentido de delimitar acepção e analisar interpretações a respeito do tema corpo e sua materialidade nos espaços sociais, visto que é pela prática, pelo trabalho, pela estética, pela saúde que são concretizados os fenômenos do corpo.

Na sequência é feita análise sobre o corpo laborioso e o corpo esculpido, com apresentação de dados coletados empiricamente com aplicação dos instrumentos: roteiro de observação do cotidiano, anamnese sociobiológica e o protocolo antropométrico.

A pesquisa empírica, em desenvolvimento, é tratada em duas dimensões, na dimensão da compreensão por meio da observação do cotidiano e conversa sobre esse cotidiano, de onde se define as categorias de percurso para análise com a finalidade de compreender o significado das formas de expressão dos sujeitos, e a tomada de dados sociobiológico permitem explicar e complementar a caracterização do perfil dos sujeitos participantes do estudo. 


\section{LUGAR DO CORPO}

Ao investigar os costumes sociais sobre os cuidados com a saúde e o trato com o corpo é necessário discutir o conceito lato de saúde e a relação com as concepções de corporeidade a partir da fenomenologia e corporalidade na abordagem materialista e considerar apontamentos realizados em pesquisas, para o trato com o corpo e saúde na sociedade contemporânea.

Corpo trabalhador ou laborioso e corpo esculpido são fenômenos do cotidiano social, em que estão consolidados hábitos da moral e higiene, e que se fazem ocultos na aparente conduta social (GLEYSE, 2006), no entanto, são os hábitos que determinam desde as práticas corporais bem como o comportamento social. A leitura de Gleyse converge ao pensamento de Foucault sobre a determinação da instituição social sobre o corpo definido pela prática social.

Aliás, as leituras de perspectiva fenomenológica evidenciam a justa acepção de corpo sujeito, porque o corpo não é, sem um homem, sem uma mulher, sem história ou lugar. Bernard (1976) publica obra de grande influência no pensamento sobre as experiências práticas e o corpo na sociedade. Seus estudos sociológicos, a partir da dança, iniciam a construção de teorias sobre o corpo social.

Jacques Gleyse aporta suas ideias na leitura de Bernard. Sua obra, iniciada publicamente em 1983, quando começa os estudos sobre corporeidade para um concurso docente na área das Ciências da Educação, tem continuidade quando Gleyse em 1997 sistematiza o pensamento sobre o verbo e a carne e escreve "A instrumentalização do corpo", memorial defendido para obter autorização para coordenar pesquisa na França.

Para Gleyse a relação carne e verbo é elucidativa sobre a essência humana. Ao discorrer sobre sua teoria , Gleyse estabelece que o ser sujeito é o ça, expressão em francês que não tem tradução exata, mas que está correlacionado com a construção do sujeito pela relação carne e verbo, o sujeito se constrói entre a carne, relativa a natureza, ao biológico, e o verbo expresso na cultura e nas práticas sociais/corporais.

A carne é - para Gleyse que labora seu pensamento também com estudos de Lacan e Freud - a materialidade concreta, o corpo biológico, onde o real se manifesta e é percebido. Onde as diferenças de sexo, cor, pele, são definidos. Na carne está a imposição do superego com a imposição institucionalizada de códigos, regras e normas sociais historicamente construídas.

$\mathrm{O}$ verbo permite o imaginário, o desejo, a criatividade. No verbo se constitui o simbólico, o linguajar. Pelo verbo transitam o ego e o id, expressos nos rituais culturais, e onde se desenvolvem as técnicas corporais. Ainda segundo Gleyse a aprendizagem social ocorre nessa relação carne e verbo, entre a natureza e a cultura.

Ao apreciar o propósito deste estudo Gleyse enuncia que, se, e somente se, é necessário estabelecer lógica de pensamento como opção teórica entre os conceitos de corporeidade e corporalidade, a forma de explicar para caracterizar essa lógica é correlacionar a corporeidade ao verbo e a corporalidade a carne. No entanto, é a observação e análise do cotidiano dos sujeitos que define o corpo em sua expressão e construção: a experiência vivida é tal distanciamento conceitual se reduz a terminologia. 
Os constructos sobre corporeidade e corpo, desde Merleau-Ponty, Mauss e Foucault, e os pensadores contemporâneos a eles bem como seus seguidores, expressam o paradoxo corpo e o processo de institucionalização desse corpo, subsumindo o sujeito nas regras e códigos sociais na evolução do tempo. Com isso o corposujeito é adjetivado no espaço temporal e assume símbolos e signos que o qualificam na sociedade, pela organização dos grupos sociais e a relação de pertencimento ou exclusão.

Gleyse (2011) faz análise do trato com o corpo na sociedade francesa do Século XI e ao apreciar a racionalização das técnicas corporais identifica três processos que podem explicar o corpo na modernidade e compreender as abordagens conceituais que envolvem o fenômeno corpóreo, a fabricação do corpo, a industrialização do corpo e a racionalização das técnicas corporais ou o corpo máquina.

Para esclarecer os processos pelos quais o corpo passa e vem passando na evolução do tempo, Gleyse usa a arqueologia do corpo e configura uma estratificação que tem na base o corpo artesanal ou poiético; seguido do corpo mecânico; e o corpo máquina situado na era da industrialização da sociedade. Ao caracterizar esta era como da hipermodernidade, Gleyse ainda define o corpo poético/estético, marcado pelo hedonismo.

No primeiro extrato arqueológico do corpo poiético, há uma estética cultural, pois como corpo artesanal, a construção desse corpo é resultante das manifestações culturais, em cada jogo, cada dança e toda prática corporal. Há uma racionalização da prática em si, para realização do movimento e preparação do corpo na manifestação, sem a preocupação científica ou, grosso modo, de racionalidade técnica.

O corpo mecânico, segundo nível da arqueologia, se movimenta pela repetição e automação do gesto, portanto, com movimentos mecânicos e repetitivos para dada função ou objetivo, a exemplo dos exercícios calistênicos e cartesianos. A exemplo da Educação Física Tecnicista e do Esporte Moderno.

A industrialização da sociedade produziu o corpo industrial, em série, a partir de um modelo, fez do corpo uma máquina com cuidados da Física e da Química para eficiência do movimento e equilíbrio funcional. Por fim, Jacques explica que nesta sociedade hipermoderna, racionaliza-se no corpo o que ainda não estava racionalizado, é o processo contínuo da estratificação arqueológica.

E nessa perspectiva o objetivo primeiro (o trato com o corpo em primeiro plano) é o poético, o estético, de caráter hedonista. O corpo performático, a que tudo escapa menos o desejo. Gleyse amplia a reflexão quando analisa a fabricação humana do corpo e diferencia claramente da fabricação da vida, de natureza divina, do corpo natural.

Estabelecem-se duas formas de pensar o corpo: na primeira, o corpo natural, a vida, em que o homem não alcança, pois é obra de Deus, o rerum opifex naturae; na segunda lógica do pensamento o manus opera, em que o homem inicia a dissecação do corpo, via medicina, e daí para frente à continuidade desse processo de manufatura do corpo que chega na industrialização do corpo, quando não existe mais a valorização do corpo natural (GLEYSE, 1997), e toda a arqueologia já anunciada.

Em análise da sociedade performática Evans; Davies; Rich (2013) tratam da pedagogia do corpo e o ressaltam, citando Heidegger, Durkheim, Weber e pesquisadores do 
campo da Sociologia da Educação. Incidem sobre a cultura da razão instrumental e da condição do sujeito ocupar o lugar do corpo frente às expectativas performativas de mercado ou o lugar ideológico do corpo belo.

O conceito de corporalidade tem sido aplicado na antropologia social e em investigações de abordagem histórico cultural desde Marcel Mauss quando trata das técnicas corporais e como em De Oliveira; M; De Oliveira, Luciane; Vaz, (2008, p. 304) que destacam a corporalidade, entendida como a expressão criativa e consciente do conjunto das manifestações corporais historicamente produzidas, as quais pretendem possibilitar a comunicação e a interação de diferentes indivíduos com eles mesmos, com os outros, com o seu meio social e natural.

Bem como Weidner Maluf (2001, p. 93) analisa o fenômeno corpo e o conceito de corporalidade se evidencia quando registra o corpo e sua dimensão em diferentes grupos sociais como a sociedade indígena e a ocidental urbana.

Os estudos acima correspondem à inquietação e investigação desse tema presente. Em busca de situar o corposujeito no tempo/espaço para compreender o fenômeno da existência humana nas dimensões social, política, cultural, sensível. Desde a etimologia de corporeidade e etimologia corporalidade pelo veio das áreas do conhecimento que demanda problemática e produção de conhecimento.

$\mathrm{Na}$ abordagem fenomenológica o corposujeito é preservado também em sua identidade social, singularidade e vivência contextual. Nóbrega (2008) que desenvolve investigações em longo prazo sobre a percepção do corpo como atitude e o movimentar-se como dinâmica do sujeito no meio social, apresenta argumentos esclarecedores a partir do conceito em Merleau-Ponty.

Nóbrega (2010, p. 37) informa que a análise sobre as questões do ser humano é privilegiada por Merleau-Ponty, que passam pela vida social, os afetos e conhecimentos via corporeidade e os procedimentos epistêmicos desse fenômeno, já anunciados em diversas obras e estudos dessa autora, que se propõe aos desafios teóricos de desenvolver o pensamento sobre esse fenômeno para além da caracterização conceitual.

Ao optar pela interpretação como procedimento metodológico Nóbrega (op. cit., p. 39) enuncia a aplicação terminológica da fenomenologia do corpo que expressa em si mesma a sua essência: o corpo sujeito e o mundo vivido, retomando Husserl e o princípio da verdade que se define e evidencia no mundo vivido e pela experiência vivida.

É sobre o corposujeito concebido na corporeidade que se investiga a aproximação com o trabalho para tratar do corpo trabalhador. Já há estudos que estabelecem os limites para analisar o corpo por ser campo de estudo pós-moderno, no entanto, é esse mesmo corpo histórico que desde sempre a humanidade o percebe na sua materialidade e historicidade onde se concretizam os fenômenos da relação sujeito e mundo.

Herold Junior (2008) elabora aporte teórico para o tema quando indica que é pelo campo do trabalho que se pode analisar o corpo e estabelecer crítica de abordagem dialética e materialista sobre o fenômeno corporeidade e sem cair no modismo alegado por muitos críticos do pós-modernismo. 
Nessa lógica, é pertinente abordar o conceito de omnilateralidade aplicado pelo pensamento materialista e já analisado em estudos anteriores (GENÚ, 2009), em que homem deve desenvolver sua faculdade mental e afetiva social por meio de uma educação voltada para suas competências globais, e que articulados ao conceito de corpo saudável, admitido na totalidade do ser, estão os aspectos materializados na dimensão ética e perpassados pelo plano político-econômico afetivo-social.

Essas dimensões perpassam o processo de educação, e de formação humana, na perspectiva da superação de um dado estágio do comportamento humano e pertencem ao desenvolvimento humano, são explicitadas em Couto (2009) quando esquematiza a relação motricidade (ação intencional, criatividade), educação (formação e integração na sociedade) e saúde (qualidade de vida, bom estado integral e estabilidade pessoal).

Na perspectiva materialista a corporalidade expressa a relação natureza corporal (que indica cultura e história) e trabalho, Saviani (2007) tece análise sobre essa relação, ressaltando que é pelo trabalho que se compreende a ontologia humana. Nesse sentido, vale discutir e consultar a natureza do trabalho e o conceito de trabalho, de forma críticoreflexiva, pois nesse estudo, qualquer dos sujeitos participantes é trabalhador, em áreas diferentes.

\section{CONSIDERAÇÕES DESSE ESTUDO: NOTAS PARA CONTINUIDADE INVESTIGATIVA}

Como estudo matricial (primeiras aproximações com a temática) merece continuidade e aprofundamento tanto teórico como prático. Analisar o fenômeno corpo, investigado por diferentes áreas do conhecimento e na linha limítrofe entre as ciências humanas e as Ciências biológicas, requer problematização a partir de um recorte teórico, espacial e temporal.

Neste estudo introdutório se utilizou os conceitos de corporeidade enunciados por Gleyse em parte de sua produção na interlocução com Nóbrega, e esses dois pesquisadores citados usam Merleau-Ponty como referência básica de suas obras; para apreciar o conceito de corporalidade na perspectiva materialista se usou De Oliveira, Vaz, Evans e Weidner Maluf. Há que se ressaltar a incipiente literatura de abordagem materialista sobre o fenômeno corpo. Ainda, nesse estudo, foi considerada a produção dos autores da matriz científica da motricidade humana como Aza, Couto, Genú e KolyaniK Filho da Rede Internacional de Investigadores da Motricidade Humana. Dessa produção teórica citada foram encontradas enunciações teóricas que correlacionam os termos corporeidade e corporalidade.

Para estabelecer parâmetros entre os termos corporeidade e corporalidade, se pode eleger como resultado desse estudo:

1- $\quad$ O critério de verdade é a prática social, a experiência percebida na relação com o outro mediado pelo meio;

2- $\quad$ O corpo é a única materialidade concreta e está condicionado as relações que estabelece, as instituições, as representações sociais; 
3- Para falar do corpo sujeito é necessário adotar o conceito de corpo fenomenal e admitir o ser na sua inteireza (ser político-social e afetivo) e incompletude (processo permanente de conscientização e desenvolvimento);

4- $\quad$ O sujeito é potencialmente e iminentemente capaz e se adapta e produz cultura, transforma e na medida em que transforma é corpo trabalhador.

$\mathrm{Na}$ genealogia dos termos corporeidade e corporalidade se localiza seu uso nessa dupla derivação, que para além da teoria do conhecimento, que origina cada um desses termos, e leitura conceitual está o trato com o corpo. Este que é corposujeito histórico e situado traz em sua essência a carne, materialidade concreta, e o verbo, a impressão da cultura com símbolos e imaginário. Na prática, o que se constata com esse estudo: se corpo artesanal ou poético como o dos sujeitos do cais do porto, é corpo que se expressa por suas técnicas corporais, pela poesia, e sonha. Se corpo estético, como o dos sujeitos fisiculturistas, é corpo esculpido pela fabricação de músculos em busca do estético.

É um paradoxo o uso terminológico corporeidade ou corporalidade para tratar as questões do corpo, porque para compreender e explicar o fenômeno social total denominado corpo, há que considerar sua totalidade dimensional e as implicações da prática vivencial. Nessa lógica as terminologias corporeidade e corporalidade não se constituem obstáculo epistêmico para falar do corposujeito. O que caracteriza o corpo é o objetivo da prática social.

Essas notas são recomendadas para estudiosos do corpo, em especial aos professores que trabalham com os sistemas não escolares como os espaços socialmente vulneráveis a exemplo dos estivadores do Cais do Porto ou daqueles que cultivam o corpo treinado, atlético, esbelto; aos docentes que trabalham com formação de professores. Aos professores que estão diretamente intervindo em espaços de formação humana.

\section{REFERÊNCIAS}

1. ALVES-MAZZOTTI, A. J. A "revisão bibliográfica" em teses e dissertações: meus tipos inesquecíveis - o retorno. In: BIANCHETTI, L.; MACHADO, A. M. N. (Org.). A bússola do escrever: desafios e estratégias na orientação de teses e dissertações. São Paulo: Cortez, 2002.

2. BERNARD, Michel. Le corps. Paris: Delarge,1976.

3. CHIZZOTTI, A. A pesquisa qualitativa em ciências humanas e sociais: evolução e desafios. Revista Portuguesa de Educação, Portugal, v. 16, n. 2

4. COUTO, José M. a. Motricidad, salud y educación: três piezas del mismo engranaje. In Genú, Marta et al (Org.). Motricidade Humana: uma metaciencia. 01 ed. Belém: EDUEPA, 2009

5. DE OLIVEIRA, Marcus Aurélio Taborda; DE OLIVEIRA, Luciane Paiva Alves; VAZ, Alexandre Fernandez. Sobre corporalidade e escolarização: contribuições para a reorientação das práticas escolares da disciplina de educação física. Pensar a Prática, v. 11, n. 3, p. 303, dez. 2008. ISSN 1980-6183. Disponível em: <http://www.revistas.ufg.br/index.php/fef/article/view/4344/4268>. Acesso em: 09 Mar. 2015. 
6. EVANS, John; DAVIES, Brian; RICH, Ema. Educando o corpo em uma cultura performática. In APPLE, M; BALL, S; GANDIN, L. Sociologia da Educação: análise internacional. Porto Alegre: Penso, 2013

7. GENÚ, M. Formação Humana: superação e transformação em educação e desenvolvimento humano. In Genú, Marta et al (Org.). Motricidade Humana: uma metaciencia. 01 ed. Belém: EDUEPA, 2009

8. GLEYSE, Jacques. Archéologie de L'éducation physique au XXéme siècle em France. Le corps occulté. Paris: L'Harmattan, 2006

9. Michel Bernard. La chair et le verbe. Corps et culture [En ligne], Numéro 5 | 2000, mis en ligne, le 24 septembre 2007. Disponível: http://corpsetculture.revues.org/730. Acesso: 25/05/2015.

10. ___ La renaissance de la "fabrication du corps" par l'exercice physique au XVIe siècle: discours, pratique, préservation d'um patrimoine, ou transgression d'un interdit? Une étude des archives du fonds ancien de la Faculté de médecine de Montpellier. Canadian Journal of History/Annales Canadiennes d'Histoire. Volume 46, number 1, Spring-Summer/printemps-été, 2011.

11. . L'Instrumentalisation du corps. Paris: L'harmattan, 1997.

12. ___ ; SOARES, Carmen Lúcia. Como se fabricam os anjos? Uma arqueologia do corpo nos manuais escolares de moral e de higiene na França, 1880-1974. Revista Brasileira de Ciências do Esporte, Florianópolis, SC, v. 34, n. 4, dez. 2012.

13. HEROLD JUNIOR, Carlos. Os processos formativos da corporeidade e o marxismo: aproximações pela problemática do trabalho. Revista Brasileira de Educação. v. 13 n. 37 jan. /abr. 2008

14. MAUSS, Marcel. As técnicas corporais. [19341. In: MAUSS, Marcel. Sociologia e antropologia. São Paulo: EPU, 1974, vol. II

15. NÓBREGA, Terezinha Petrucia. Uma fenomenologia do corpo. São Paulo: Ed. Livraria da Física, 2010.

16. Corpo, percepção e conhecimento em Merleau-Ponty. Estudos de Psicologia, 2008, 13(2), 141-148.

17. WEIDNER MALUF, Sônia. Corpo e corporalidade nas culturas contemporâneas: abordagens antropológicas. Esboços - Revista do Programa de Pós-Graduação em História da UFSC, [S.I.], v. 9, n. 9, p. pp. 87-101, jan. 2001. ISSN 2175-7976. Disponível em: <https://periodicos.ufsc.br/index.php/esbocos/article/view/563/9837>. Acesso em: 09 Mar. 2015. 